\title{
The Evolution of an Industrial Sector with a Varying Degree of Roundaboutness of Production
}

\author{
Andersen, Esben Sloth
}

Document Version

Final published version

Publication date:

1996

License

CC BY-NC-ND

Citation for published version (APA):

Andersen, E. S. (1996). The Evolution of an Industrial Sector with a Varying Degree of Roundaboutness of Production. DRUID - Danish Research Unit for Industrial Dynamics. DRUID Working Paper No. 96-13

Link to publication in CBS Research Portal

\footnotetext{
General rights

Copyright and moral rights for the publications made accessible in the public portal are retained by the authors and/or other copyright owners and it is a condition of accessing publications that users recognise and abide by the legal requirements associated with these rights.

\section{Take down policy}

If you believe that this document breaches copyright please contact us (research.lib@cbs.dk) providing details, and we will remove access to the work immediately and investigate your claim.
} 


\title{
$\mathbf{D}_{\text {ANSH }} \mathbf{R}_{\text {ESearch }} \mathbf{U}_{\text {NIt For }} \mathbf{I}_{\text {NDUSTRIaL }} \mathbf{D}_{\text {YNAMICS }}$
}

\author{
DRUID WORKING PAPER NO. 96-13
}

The Evolution of an Industrial Sector with a Varying Degree of Roundaboutness of Production

by

Esben Sloth Andersen

October 1996 


\title{
The Evolution of an Industrial Sector \\ with a Varying Degree of Roundaboutness of Production
}

By

\author{
Esben Sloth Andersen \\ Department of Business Studies \\ Aalborg University \\ Fibigerstræde 4 \\ DK-9220 Aalborg Oest \\ Tel (+45) 98158522, Fax (+45) 98156013 \\ E-mail: esa@business.auc.dk \\ Paper presented at the \\ International Schumpeter Society Conference, \\ Stockholm, 3-5 June 1996
}

\begin{abstract}
The evolutionary model presented in this paper depicts an industrial sector with a varying degree of economic roundaboutness, i.e. vertical division of labour between producers and users of different types of intermediate products that are ultimately used for the production of a single final product. To include this vertical aspect of industrial dynamics, the model adds the concept of production trees to the evolutionary models of Schumpeterian competition. The specification of this concept suggests the use of the notions of graph theory and the related algorithms of computer science in the treatment of industrial novelty, including structural innovations. Although the model is developed within the Nelson and Winter tradition, the introduction of the 'Austrian' issue of roundaboutness implies a major extension of the research agenda, including production-structure innovations, the emergence and functioning of markets for intermediate products, ways of coping with the instability of upstream markets, the spread of the effects of an upstream innovation, and the measurement of the degree of roundaboutness and of overall productivity. The model reflects a Schumpeterian version of the Böhm-Bawerkian vision of the emergence of increased long-term roundaboutness of production. The Schumpeterian approach implies an innovation- and entrepreneur-driven process of vertical disintegration and reintegration.
\end{abstract}

\section{Keywords}

Roundaboutness, production graphs, evolutionary economic modelling, Nelson and Winter

\section{JEL classification}

L0, L1, B25 


\section{Contents}

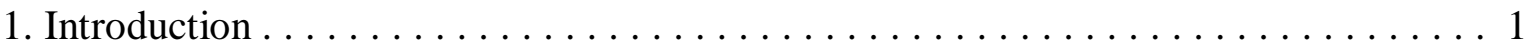

2. Production trees as nested hierarchies of tasks $\ldots \ldots \ldots \ldots \ldots \ldots \ldots \ldots \ldots$

3. Formal representation of evolving production trees $\ldots \ldots \ldots \ldots \ldots \ldots \ldots$

4. Production trees in a Nelson and Winter like model $\ldots \ldots \ldots \ldots \ldots \ldots \ldots \ldots \ldots$

5. Types of roundaboutness in the vertical model $\ldots \ldots \ldots \ldots \ldots \ldots \ldots \ldots \ldots$

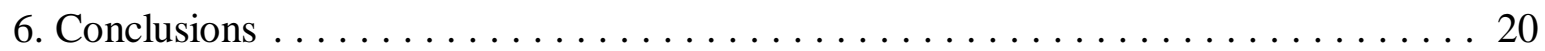

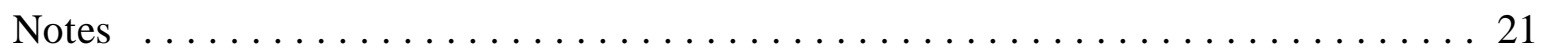

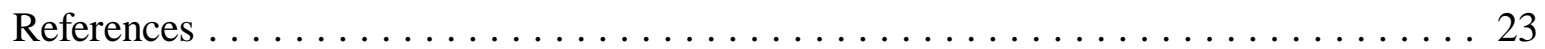




\section{Introduction ${ }^{1}$}

Because of its pioneering status and its relative simplicity, the model of horizontal Schumpeterian competition developed by Nelson and Winter (1982, chs. 12-14) has obtained a prominent role in defining what evolutionary economics is about. From this model $^{2}$ we know that economic evolution can be depicted as a process in which firms follow rules or procedures that can occasionally be mutated or adapted. We also know that an important example of economic evolution takes place within an industry (or a one-sector economy) where new process techniques are introduced and imitated. These and other aspects of the Nelson and Winter model have to some extent defined a 'paradigm' for further research on the conditions of R\&D as a determinant of industrial concentration, dynamic competition in alternative technological regimes, the relationship between innovators and imitators, etc. ${ }^{3}$ A variant of the Nelson and Winter model (1982, ch. 9) has also had some influence in promoting evolutionary growth theory. ${ }^{4}$

The model proposed in the present paper suggests a much more vertical definition of the tasks of evolutionary economics. Although it is deliberately held as close as possible to Nelson and Winter, the present model of a sector with a varying degree of roundaboutness of production points towards a major extension of the evolutionary research agenda. The model emphasises that evolution concerns large sets of rules and procedures whose mutation or adaptation leaves plenty of room for coevolutionary specialisation of firms. Such a process can, however, only to a limited extent take place within an individual industry (or in a one-sector economy). Instead it promotes a complex and fluctuating division of labour between firms. In the evolution of such an economic system, vertical cooperation between users and producers of intermediate products is just as important as horizontal competition between producers of the same product. Further issues emerging from the model are production-structure innovations, creation and functioning of markets for intermediate products, ways of coping with the instability of upstream markets, and measurement of the degree of roundaboutness and of overall productivity.

The specification of the vertical parts of the model draws eclectically on many sources. One of the first is Schumpeter who developed his own theory in a confrontation not only with Walras general equilibrium system but also with Böhm-Bawerk's theory of roundabout methods of production as a partial explanation of the positive interest on capital.5, Unfortunately, Böhm-Bawerk's (1913) massive attack on Schumpeter's theory made it impossible to make an immediate development of the vertical, BöhmBawerk like dimension of the Schumpeterian approach. It was instead Young (1928) and Stigler (1951) who brought together the themes of increasing returns, division of labour and roundabout methods of production. But they did so in a non-Schumpeterian way 
by considering gradually emerging increasing returns to production rather than increasing returns to discrete innovations. More direct inspiration has been drawn from Gerybadze (1982, chs. 3 and 5) who turned the Nelson and Winter model towards the modelling of product development and the interaction between two vertically linked industries. Similarly, Chiaromonte and Dosi (1993) developed a two-sector evolutionary model based on the Nelson and Winter model. But still we find in Gerybadze, Chiaromonte, Dosi and others no real treatment of the evolution of economic roundaboutness and the related externalities. These themes are still mainly touched upon in relation to Young and Stigler, for instance by new institutional economics (e.g. Langlois and Robertson, 1995), new growth theory (from Romer, 1986 and onwards) and new classical microeconomics (e.g. Yang and Ng, 1993).

The apparent inability of the Nelson and Winter tradition to respond to these challenges is somewhat surprising since the Nelson and Winter model applied both these increasing returns and externalities. It operates with increasing returns since the probabilistic costs of an innovation are given once and for all while there are no extra costs involved in its broader or narrower application of an innovation. It operates with external economies since an innovation can be imitated with very low probabilistic costs. But the Nelson and Winter model seems to be so closely bound to the concept of an industry or a sector with homogeneous inputs and a homogeneous output that e.g. the idea of the increasing interfirm division of labour in the upstream of a growing market is very difficult to cope with. The present model tries to remedy this situation primarily by means of the concept of a production tree. Based on this concept, it is possible to model a production system that is characterised by an evolving technical and economic division of labour. Technical division of labour is the splitting up of a production task in two or more subtasks. Economic division of labour is the distribution between firms of two or more subtasks. While the former may include both intrafirm and interfirm specialisation, the latter only treats interfirm specialisation.

The model is presented in a roundabout way. In section 2 the concept of production trees is presented informally. The intuition about production trees is formalised in section 3, which applies the terms of graph theory and the related algorithms of computer science. In this context it becomes obvious that we are able to handle different kinds of novelty, including process and product innovation in relation to a given production tree as well as the structural transformation of production trees. Given these ways of representing production trees and their transformation, the task of section 4 is to introduce them into the framework of a Nelson and Winter like model. The resulting vertical model of Schumpeterian competition suggests several important areas of analysis - including vertical disintegration as a way in which the effects of innovation can be spread throughout an industrial sector, but also a method that involves serious 
coordination problems. Section 5 deals with the many ways of measuring the roundaboutness of production, and the hypotheses that these measures can help to formulate.

\section{Production trees as nested hierarchies of tasks}

The evolution of the division of labour can most easily be described in terms of human problem solving (in relation to figure 1). Think of a Robinson Crusoe placed in a virgin forest and in need of one cubic metre of firewood (and other necessities which are not depicted in figure 1). One method is to break small branches off the trees by hand. In this way the task is solved through a single activity (activity 1). Another method involves a decomposition of the task into two subtasks: first a stone axe is produced (activity 2), then it is used in wood chopping (activity 1). An improvement of the method involves the specification of axe maintenance - e.g. axe grinding (activity 3 ). Further improvements can both take place within each of the three activities and by adding further activities to the system of production (possibilities are marked by small, open-ended branches).

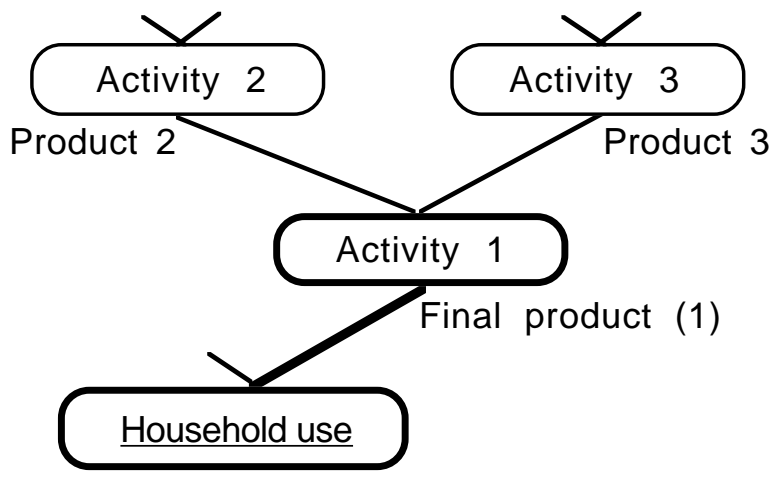

Figure 1. An initial production tree with potential extensions.

The example of producing a cubic metre of wood is taken from Böhm-Bawerk (1921, $113 \mathrm{f}$.) who extends it into modern times by pointing out that a much more complex method is necessary if wood cutting is to be done with the help of a steel axe: iron ore as well as fuel and tools for iron smelting must be provided; then comes the smelting and improvement of the iron, and the forming, hafting and sharpening of the axe; finally, the axe can be used (and maintained) by forest workers. ${ }^{6}$ The steel axe method can easily be made more complex since each of the processes of axe making can be further subdivided. For instance, special machines can be made for mining, steel works, tool making, sharpening of axes, etc.

Böhm-Bawerk follows other Austrian economists by starting from the task specified by the end user. This 'Austrian' approach is designed to cut across the dividing lines of firms and professions dealing with wood cutting, grind stone production, axe handle 
making, axe head forging, steel making, mining, etc. ${ }^{7}$ It does so by defining a tree-like structure of tasks (a nested hierarchy of tasks) that shows how each subtask directly or indirectly contribute to the basic task. In the case of firewood, the end task may be cooking of food in household production (level 0). This can be seen as the root of a production tree that depicts labour activities and their intermediate inputs; natural inputs are not depicted (see figure 2).

The root is connected to the tree's first node (the activity of wood cutting) through a branch that specifies the product (definitions of one cubic metre of firewood). Activity 1 (level 1) is connected to two other activities (level 2 with axe provision and axe maintenance). Level 3 of the production tree is defined by the needs of the activities of level 2. Activity 3 only needs one input (grinding stones) while activity 2 needs two inputs (axe heads of steel and axe shafts of wood). Both activity 5 and 6 (shaft making and grindstone-making) as supposed to be performed by labour and natural resources alone while activity 4 (steel-axe-head making) needs steel and the tools of a blacksmith. Level 4 consists of the activities solving these tasks (steel making and tool making). These activities have not been decomposed in figure 2.8

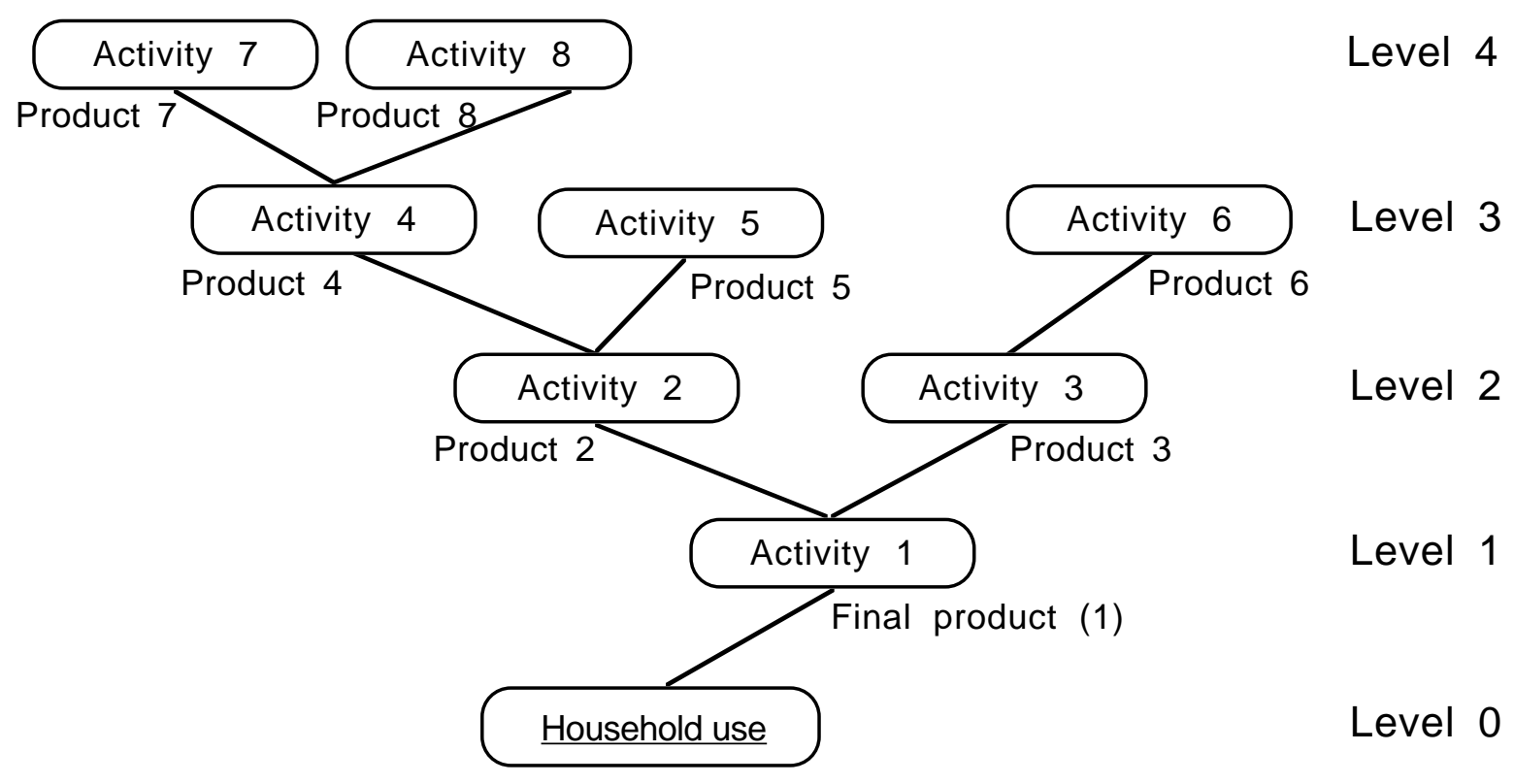

Figure 2. An extended production tree.

The existence of the complex activity of steel production at level 4 clearly indicates that the production tree does not include all the possibilities of decomposing the task of wood cutting. On the contrary, even less complex subtasks can be further divided into sub-subtasks, and this process can continue recursively. However, if basic technology, management strategy (e.g. crafts organisation or Taylorism), and scale of production are more or less given, managers will operate as if they were able to define primitive subtasks. 
This viewpoint is driven to the extreme by Taylor $(1911,39)$ who also applies the concept of tasks. He states: 'Perhaps the most prominent single element in modern scientific management is the task idea'. However, Taylor narrows down the concept by defining that 'a task specifies not only what is to be done but how it is to be done and the exact time allowed for doing it.' Such a short-term definition makes the concept of tasks irrelevant in an evolutionary context. In the present paper a task simply defines 'what is to be done', e.g. an intermediate product with a certain function for the user. The questions of 'how it is to be done' and 'the exact time allowed for doing it' is fixed for a given firm in a given period. But the firm is always looking for better ways of doing its main task and for a new and more profitable main task.

The open-ended definition of tasks becomes especially important when we turn from technical to economic division of labour (see figure 3). To the consumer the important thing is the price and quality of firewood, and not (normally) the methods by which it is produced. This means that the producer is free to decide how the task is to be solved. At a certain point of time (probably a hundred years ago), the firewood producer has decided to cover axe maintenance and grindstone production while axes are bought from axe producers. In their turn, axe producers decides to make shafts, axe heads and even special tools, while steel is bought from steel producers.

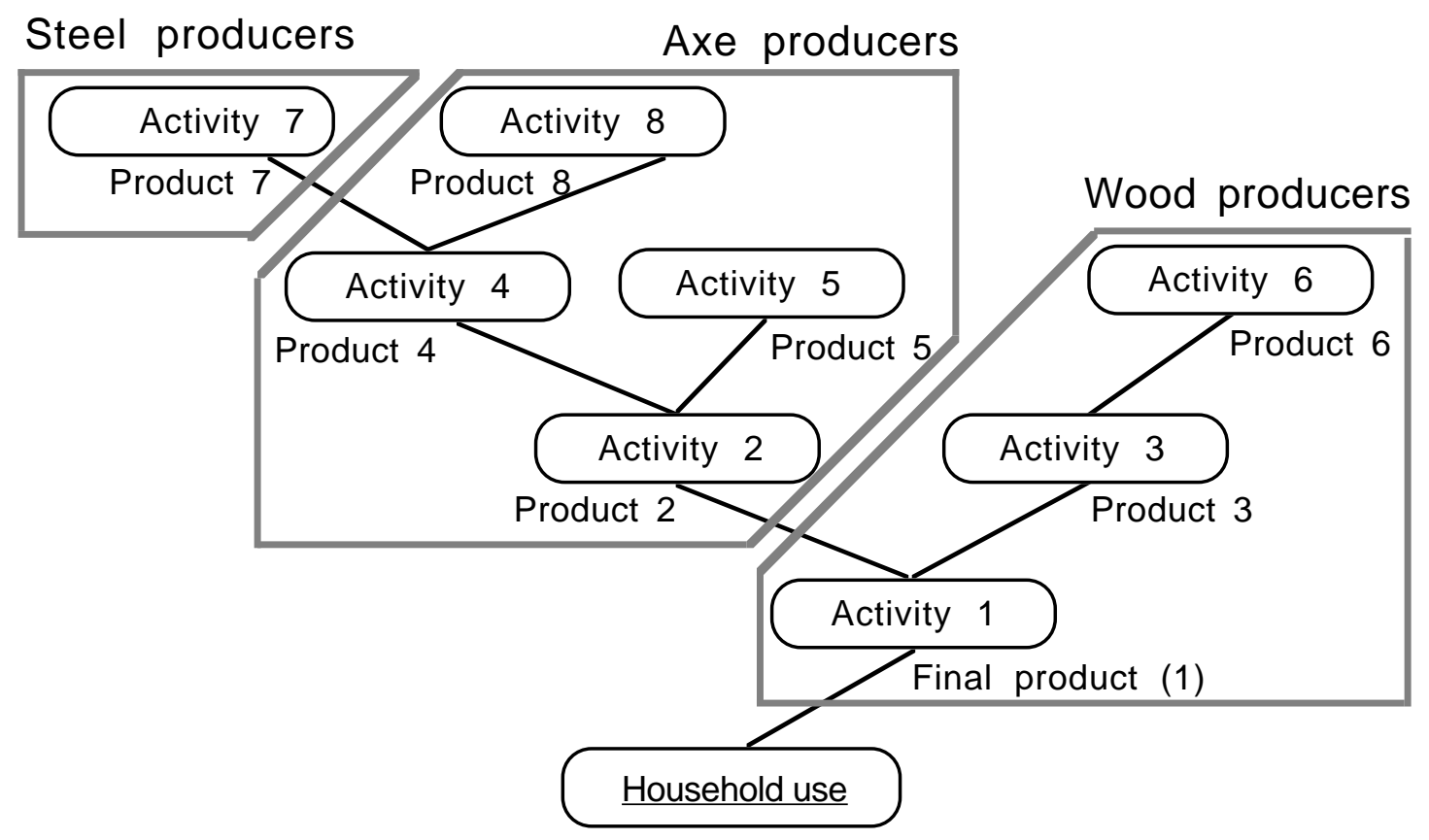

Figure 3. Example of a simple production/industry tree.

The situation depicted in figure 3 is obviously not fixed in the long run. If there is sufficient demand, all three groups of producers will be able to diminish the scope of their activities and instead formulate tasks for their emerging suppliers. These new suppliers will, in their turn, tend to subdivide the tasks that they are facing. In this way 
the process can go on until the diminishing sizes of the submarkets exclude any further technical and economic division of labour. This account for the process is really an application of Adam Smith's famous theorem 'that the division of labour is limited by the extent of the market'. It is a repetition of Stigler's $(1951,189)$ hypothesis 'that vertical disintegration is the typical development in growing industries, vertical integration in declining industries.'

The Stigler hypothesis can be criticised from several viewpoints, but a basic issue is whether the production tree is really representing the most important aspects of interdependent production. As is well known from input-output analysis, key sectors like steel making is supplying many economic activities - in the present case potentially the production of rotating grinding stones and axe-making tools as well as axe head production. If we emphasise this aspect of production, the production tree will become transformed into a production network with much more complex interdependencies than has hitherto been discussed.

Another problem can be seen if we compare the decomposition of tasks emerging around the stone-axe-based production of figure 1 and the steel-axe-based production of figure 2. Although the upper levels of the trees look like each other, we are largely facing two different trees. In other words, there is an element of 'creative destruction' in the transformation from one cutting technology to another. This fact has especially been emphasised by Schumpeter $(1934,216)$ who said: 'Our question is: does this whole development which we have been describing proceed in unbroken continuity, is it similar to the gradual organic growth of a tree? Experience answers in the negative. It is a fact that the economic system does not move along continually and smoothly.'

In the Schumpeterian vein, Langlois and Robertson (1995) have argued that the Stigler hypothesis is only covering relatively limited experiences like the initial, productinnovation-oriented phase of automobile production. The really important transformation of the production tree in order to support mass production presupposed a high degree of standardisation and integration.

These problems for naive versions of production trees should not lead to an abandonment of them. They are well-suited for a first analysis of the evolving structure of production in terms of an open-ended human problem solving (à la Simon, 1981). They are also useful in showing that firms and industries are not fixed entities with welldefined tasks but are instead characterised with a varying and evolving portfolio of activities. Finally, production trees are useful in promoting the development of models that show how interfirm division of labour can be an important method for spreading the benefits of innovations across the economic system. When these issues have been explored, the different complications can be dealt with. 


\section{Formal representation of evolving production trees}

To be able to handle production trees effectively, we need a more formal treatment of them. ${ }^{9}$ There is only a short step from the production tree of e.g. figure 2 to a more formal treatment. The figure can simply be considered as a picture of a set-theoretic graph which consists of a set of nine nodes, $\{0,1,2,3,4,5,6,7,8\}$, and a set of eight branches that connects some of the nodes, $\{(0,1),(1,2),(1,3),(2,4),(2,5),(3,6),(4,7)$, $(4,8)\}$. This particular graph is also an oriented tree since there is a unique root (node 0 ), since all nodes are connected by branches, and since there are no cycles in the graph.

The graph is, furthermore, a binary tree since each node has at most one downgoing 10 and two upgoing branches. In other words, each product is produced by means of zero, one or two intermediate products (however, the root node has exactly one upgoing branch). The nodes connected by a given node by upgoing branches are often called its descendants while the node connected by a downgoing branch is called its predecessor. The nodes of a binary tree are ordered in levels (distances from the root), and the left descendant of a node is distinguished from the right one. Therefore, any activity and product can be described unambiguously: e.g. activity 8 in figure 2 is described from the root upwards as right, left, left, right (or RLLR). With a string of 10 characters, more than a thousand different nodes can be named (e.g. RLLR - - - - - and RLLRLLLLLL). With a string of 20 characters, more than a million different nodes can be named. The nomenclature is illustrated by figure 4 (below). This figure includes, however, an extension which will be explained later.

Binary trees are examples of a much larger class of ordered trees (cf. Knuth, 1973, 305422). In such trees the branches are numbered from left to right; if the leftmost branch of any node is called ' 1 ', activity 8 in figure 2 can be described as 2,1,1,2. The application of general ordered trees allows the treatment of cases where the number of upgoing branches differ radically between the different nodes. For instance, a large number of upgoing branches may be related to the root (household use) while other nodes have fewer upgoing branches. In this case the production tree takes the visual form of a production bush. For the subtrees of the bush it is convenient to assume that they take the form of $n$-ary trees, i.e. trees where each node has at most $n$ upgoing branches. A unary tree, or a production chain, is a tree in which all nodes have zero or one upgoing branches. Binary trees represent the simplest non-linear production structure, and they are obviously serving graphical and computational convenience rather than economic realism.

If we have defined a 'mother tree', we can describe the specialisation of a firm (cf. figure 3 ) in two ways. First, we can describe the specialisation by the intrafirm nodes and branches. For instance, an axe producer of figure 3 is defined by the set of nodes: $\{2,4$, 
$5,8\}$, and the set of branches: $\{(2,4),(2,5),(4,8)\}$. In relation to the mother tree, it is obvious that the output of the firm is $(1,2)$ and the input is $(4,7)$. Second, the specialisation can be described by interfirm relationships in terms of output and input (e.g. $(1,2)$ and $(4,7))$. Given the method of production depicted by the mother tree, the intrafirm activities and relationships can be found immediately. This is illustrated by figure 4 which - apart from a small change - corresponds to figure 3.

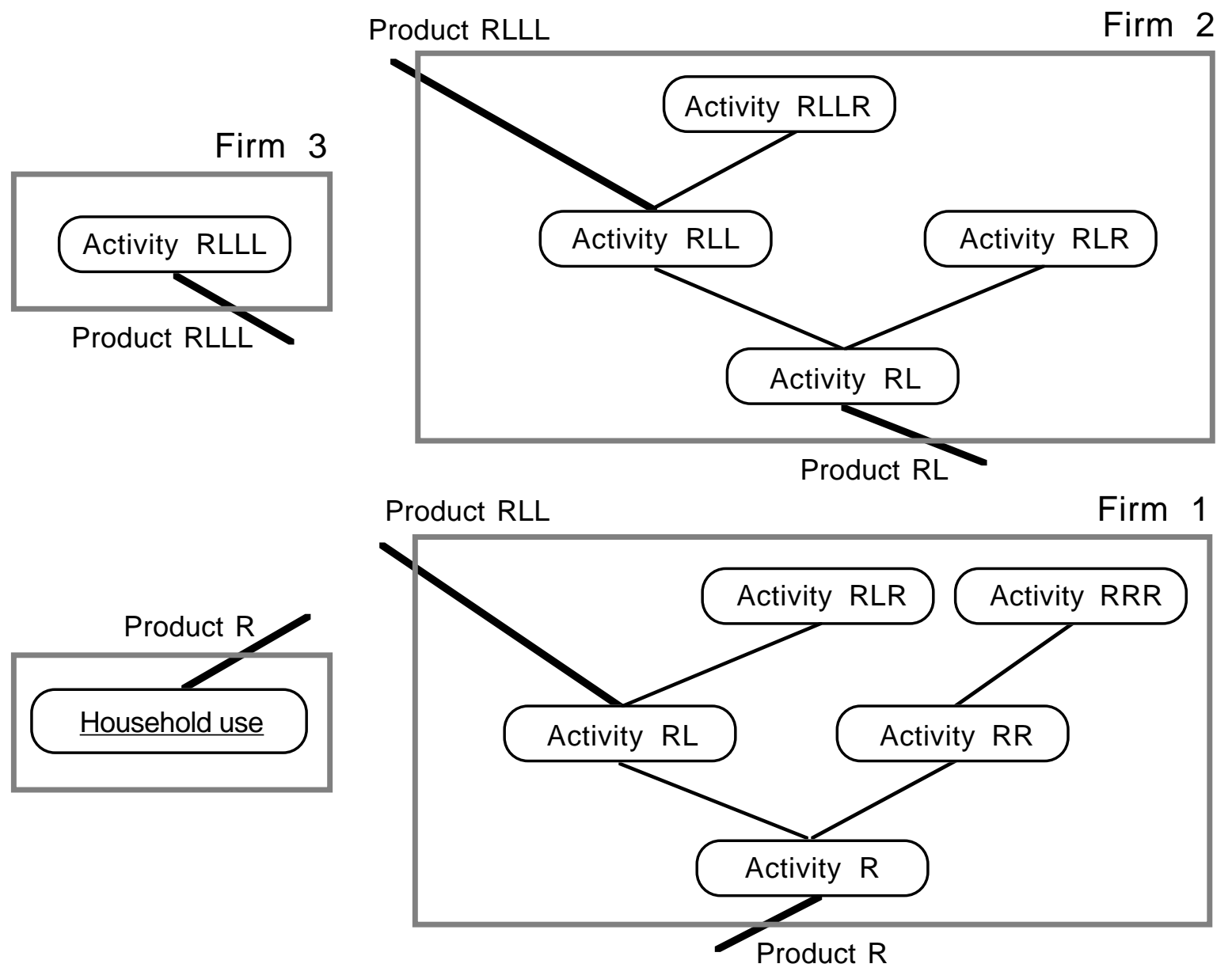

Figure 4. Firm production trees - latent parts are not shown.

(There is a matching problem between two of the firms.)

Figure 4 demonstrates a division of labour between a household and three firms. The household buys product $\mathrm{R}$ which is sold by firm 1. Firm 2 buys product RLLL which is sold by firm 3. But there is a matching problem between firm 2 and firm 1. Firm 2 sells product RL (e.g. shafted axes) while firm 1 buys product RLL (e.g. axe heads). This problem can be solved in several ways. First, firms 1-3 are not the sole firms in the economic system. Firm 4 might provide firm 1 with product RLL. Second, the model of the firm may be changed so that it is allowed to sell multiple products. In this case it can produce product RLL for sales as well as for its own use. Third, and most interesting, firm 2 may induce firm 1 to give up its activities RLR and RL (shaft production and 
shafting of axes). This revision of the division of labour can in the main be decided on the basis of productivities and prices, but there is an element of persuasion since the use of the market instead of intrafirm production implies several uncertainties.

The nodes and the branches of production trees are normally weighted. Nodes are weighted by the quantity of labour needed for producing one unit of the output of the activity. This means that $a_{i j t}$ units of labour are necessary in period $t$ for firm $i$ s production of one unit of $j$ (an intrafirm intermediate product or a marketed output). Branches are weighted by the 'quality' of the product, i.e. by the quantity of the intermediate product needed by the receiving node for producing one unit of its output. To be more specific, $b_{i j t}$ units of product $j$ of firm $i$ are necessary for the user's production of one unit of its own output in period $t$. In the simplest case the weights of all branches are 1, i.e. one unit of each of the intermediate products in the tree is needed for producing one unit of final output.

We are now ready to describe changes in production tree. Each firm is characterised by an initial production tree (like figure 2) with related weights of nodes and branches. In each period the firm makes its production and its specialisation decisions in relation to this production tree. However, the firm is also performing a systematic search (R\&D) in order to improve its production tree. The results of search activities are related to the effort of the firm in a probabilistic way (like in the Nelson and Winter models). An innovative success of a firm is distributed probabilistically across the activities represented by its production tree.

Three things can happen because of an innovative success: a process innovation, a product innovation and a structural innovation. A process innovation decreases the quantity of labour needed to produce a unit of output of the activity, i.e. $a_{i j, t+1}>a_{i j t}$. A product innovation decreases the quantity of the product needed to produce a unit of output of the using activity, i.e. $b_{i j, t+1}>b_{i j t}$. This kind of innovation has more repercussions than the former since it reduces the necessary labour not only of the producing activity but also of all the direct and indirect descendants of the activity higher up in the tree. A structural innovation is either creative or 'destructive', i.e. it adds or substitutes branches and nodes.

Structural innovations are more complex than the other kinds of innovation. A creative structural innovation can only concern a node with zero or one upgoing branches. The innovation means that the existing node $(j)$ becomes connected to a new node $(k)$ by a new branch. At the same time the quantity of labour necessary to produce one unit of output is e.g. shared equally between the two activities: $a_{i j, t+1}=a_{i k, t+1}=a_{i j t} / 2$. A 'destructive' structural innovation introduces a new node $(j ')$ that substitutes another node $(j)$ as the supplier of a using node $(k)$. To be successful the new node must have 
lower aggregate labour costs and/or higher quality seen from the viewpoint of the using node.

When a firm has made an innovation, it has to decide how to react. The first possibility is to abandon the innovation because it is considered inferior when compared to the given technology of the firm. The second possibility is to apply the innovation within the firm's given set of activities. The third possibility is to change the specialisation of the firm in order to concentrate its productive capacity in exploiting the innovation. To be successful, the third strategy presupposes that other firms make a complementary specialisation so that they are able to buy the product offered by the innovative firm.

To summarise the account for the evolution of binary production trees, it is helpful to see how figures 1-3 are related to each other. First, it should be noted that the basic characteristics of new products and activities are solely determined by their place in the binary tree (which we shall again describe according to the left-right nomenclature). This means that if an activity RL exists (see figure 1), then a newly invented activity RLL can deliver an intermediate product which can serve the RL activity. If yet another structural innovation leads to the product RLLR, then this product indirectly serves RL production.

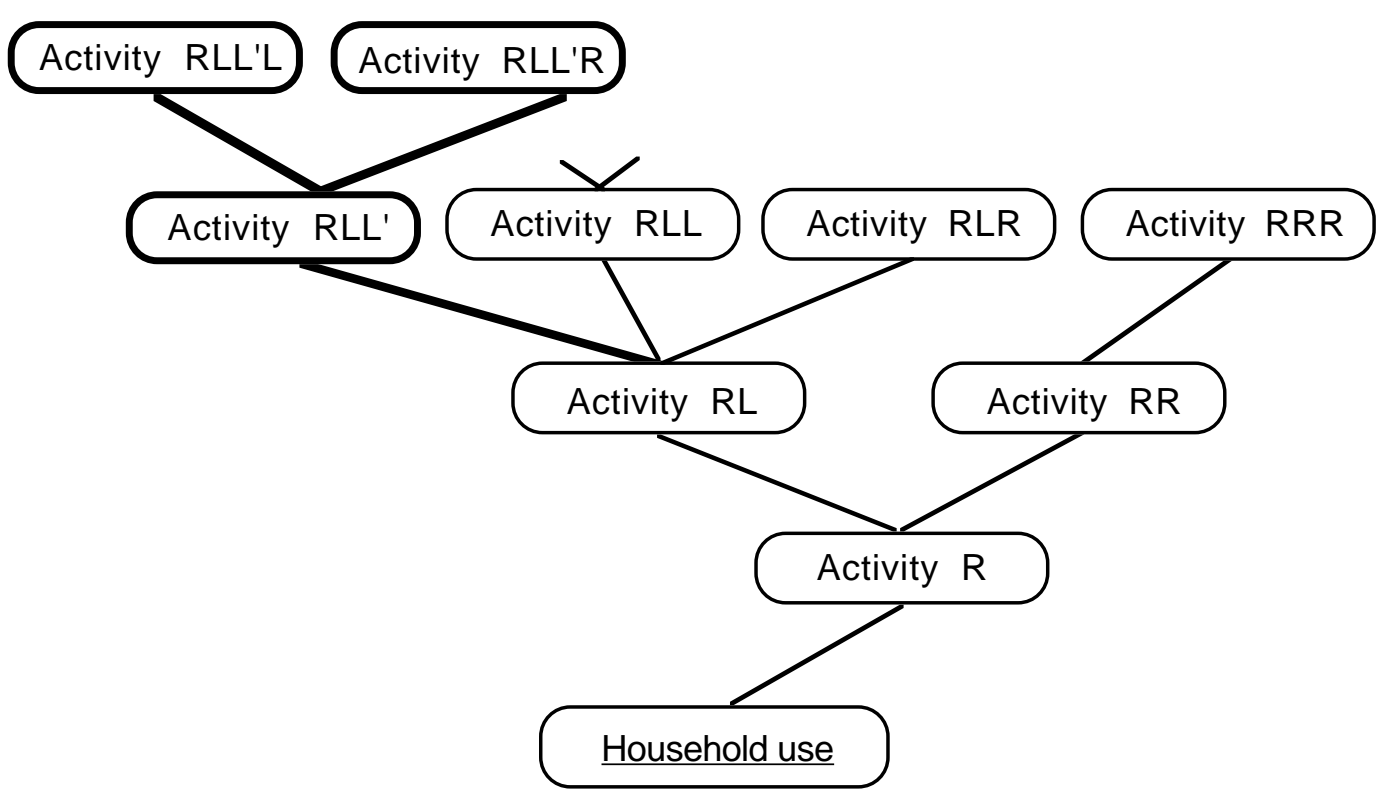

Figure 5. A binary production tree with an alternative subtree.

According to the Böhm-Bawerkian interpretation, figure 1 represents stone-axe-based wood cutting. As the tree is drawn, this gives no problems for activity RLR (shaft production) and activity RRR (grindstone production). However, the activities supporting activity RLL (axe head production) are influenced by the character of the type of axe heads. In the case of stone axes, RLLL might be the mining of flint stone and RLLR might be tools for flint axe production. To move to figure 2 interpreted as steel- 
axe-based production, we first need a 'destructive' structural innovation that transforms RLL (axe heads of stone) into RLL' (axe heads of steel). The latter product cannot be served by the same products like before; e.g. we need RLL'L (steel production) rather than RLLL. This shows that to combine figure 1 and 2, we need to think in terms of a binary tree with alternatives like in figure 5 . Here the novel steel-axe-head production is marked by thickly drawn branches that is directed to the left as is the original stone-axehead production.

According to the example of wood cutting, activity RLL'L is representing steel production which is normally considered to be a key sector in the system of production. From the viewpoint of input-output tables, this means that steel production delivers its product(s) to a large number of customers. This kind of steel production is not conceivable as an appendix to wood cutting. The problem is how to represent such key sectors without removing the advantages of formal production trees. One possibility can be applied in large-scale studies which deal with what was earlier called a production bush, i.e. multiple production trees that are all rooted in final consumption. Key sectors can here be defined as general-purpose elements of the multiple trees. For instance, we can define product RLL' as the same in all the trees. This means that the subtrees defined by RLL' is also the same in all the trees. Firms specialising in RLL' are thus able to supply all firms which to a smaller or larger degree needs RLL'. Another treatment of key sectors makes use of production externalities in the following sense: An innovation concerning RLL' influences not only the productivity or quality of RLL' production but also the productivity or quality in other parts of the production tree (and in other parts of the production bush). Firms are supposed to organise in a way which internalises parts of this externality. For instance, steel firms are supposed to take into account the externalities between different kinds of special steel.

\section{Production trees in a Nelson and Winter like model}

The ideas and formalisms presented in sections 2-3 can be introduced in a Nelson and Winter like model. Before we do so it is convenient to give a short summary of a typical Nelson and Winter model of Schumpeterian competition (cf. Nelson and Winter, 1982, chs. 12-14; Winter, 1984, Andersen, 1994, ch. 4; Andersen, Jensen, Madsen and Jørgensen, 1996). ${ }^{11}$ The Nelson and Winter model deals with the evolution of the production techniques (and potentially other behavioural rules) of an industry with $n$ firms that produce a common, homogeneous product under production conditions characterised by constant returns to scale. The Nelson and Winter model describes how the state of the industry in period $t+1$ is found when the state of period $t$ is given. The two states are marked by (1) and (17) in figure 6 . In the simple case depicted, the state of the industry is defined by the stock of physical capital and the capital coefficient of 
each of the firms of the industry. The capital coefficient is the reciprocal of the capital productivity $\left(A_{i t}=1 / a_{i t}\right)$. Thus the maximum output of firm $i$ in period $t$ is $Q_{i t}^{\max }=A_{i t} K_{i t}$. Firms produce according to a rule of full capacity utilisation.

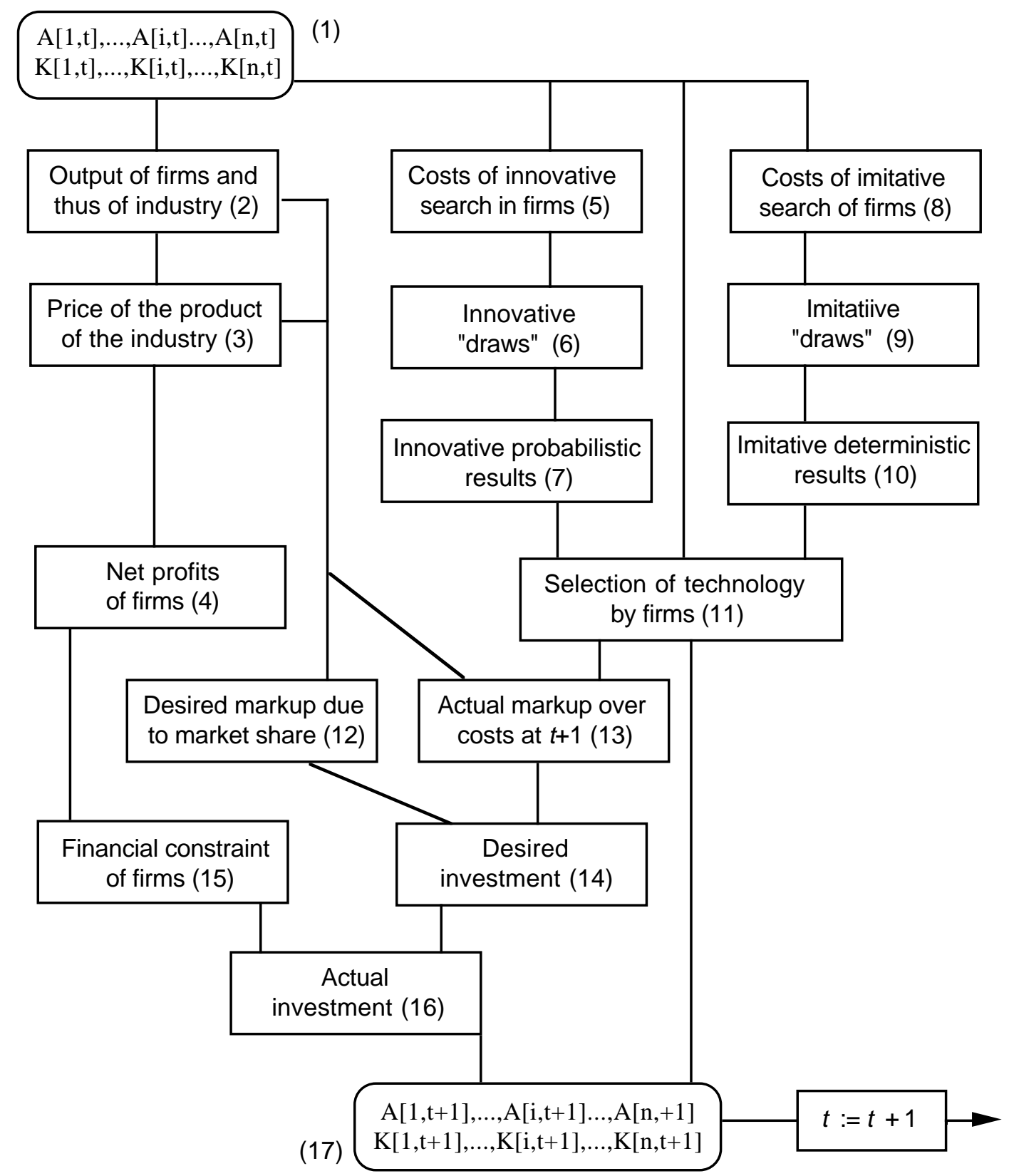

Figure 6. The computational structure of a typical Nelson and Winter model.

There are three major steps in the (Markovian) computation of the state transformation. First, the present state is used to define a simplistic short-term economic process in the industry whereby market shares, price, and profits of firms are found (calculations 2, 3 and 4 in figure 6). Second, firms perform R\&D and the outcome is determined through a mix of probabilistic and deterministic calculations (calculations 5-11). The probability of success in innovation and imitation depends on the respective search costs and the difficulty of innovation/imitation in the industry. An imitative success means that the 
firm gets access to the best-practice technique in the industry (calculation 10). The outcome of an innovative success is probabilistically determined (calculation 7); it depends on the character of technical change in the industry ('science based' or 'cumulative technology'). The attempts to improve productivity end with a comparison between the capital coefficients obtainable by the technique inherited from the last period and the outcomes of imitative and innovative search; the technique with the best productivity is chosen (calculation 11). If the technique is changed, it will determine capital coefficient, $A_{i, t+1}$, for the next period (disembodied technical change). Third and last, we come to the investment decision. Firms expand their capacity in relation to their profitability - partly with the help of banks (calculation 15). However, the expansion of firms with a large market share is constrained by the fact that the effect of expansion on the market price is taken into account (calculation 12-14).

It is obvious that there are no elements of a production tree in the Nelson and Winter model. However, in the Nelson and Winter (1982, chs. 4-5) theory of the firm we find a much more complex account. According to full theory, each firm is based on a large number of interdependent routines which are performed by the employees. The exposition of the theory of the firm follows that of Schumpeter: it starts from an analogue of Schumpeter's 'circular flow' at the intrafirm level; then the processes of change are introduced into this setting; finally the possibility of routines for making innovations is discussed. In the Nelson and Winter model of Schumpeterian competition, all this intrafirm diversity has been reduced to a single evolving production technique and a set of fixed parameters of decision-making. An explanation for this reduction of intrafirm complexity is that the environment of the industry (markets for products, factors, and finance) is highly simplified. Extra complexity with respect to the specification of firms would just make the model more confusing. But in the present context Nelson and Winter's verbal account for intrafirm complexity can be used as a starting point for the introduction of production trees and the emergence of interfirm division of labour.

The simplest way of formalising the Nelson and Winter theory of the firm in a way which opens up for a subsequent specialisation of firms is to consider the overall task of producing the final product on the industry as consisting of a series of $m$ subtasks which can either be done in parallel or in series like in a production tree. To simplify we assume that the different production tasks are performed by means of labour alone, or by labour assisted by intermediate products that are directly or indirectly produced by labour alone. For each task $j$ of firm $i$, it has in each period $t$ a specific production technique which is characterised by its labour productivity, $a_{i j t}$, i.e. the amount of labour needed in this task for the production of one unit of the output of this task. In other words, all employees are able to perform all intrafirm tasks at the firm level of 
productivity. In the case of unitary qualities of the output of all the tasks ( $b_{i j t}=1$ for all $j$ ), the total amount of labour needed for the production of a unit of the product sold by the firm is simply the sum of the labour productivities of all the $m$ tasks of intrafirm production.

The question is how to define the capacity constraints on firms when output is produced by means of labour alone. To keep the present model as close as possible to Nelson and Winter, it is assumed that the firms has a stock of employees that has been trained to function with respect to all the activities of the firm. This training is paid by the firm, and the costs may e.g. correspond to one year's salary. Before the training has taken place, the newly employed workers are assumed to be unable to produce anything. An expansion of the firms capacity thus implies financial requirements. Another consequence of the firm's investment in human capital is that it makes longterm contracts with its employees. All this means that the stock of employees, $K_{i j t}$, functions like the stock of physical capital in the Nelson and Winter model. Thus, if a firm only performs a single task $j$, its maximum output is $Q_{i j t}=\frac{1}{a_{i j t}} K_{i t}$.

We are now ready to study the consequences of task-specific technical change within firms. To make the analysis as simple as possible, we shall assume that all the firms of the industry are initially identical with respect to level of employment, production structure and task-specific productivities. They sell only the final product and buys no intermediate products. Furthermore, all intermediate products and the final product has unitary quality. In this case the structure of the production tree becomes irrelevant. Each firm simply have to produce one unit of each of the intermediate products to be able to produce one unit of the final product. This means that the labour productivities can be added so that $a_{i t}=\sum_{j=1}^{m} a_{i j t}=\frac{1}{A_{i t}}$.

This formulation apparently shows that the vertical model has been reduced to the Nelson and Winter model. There is, however, an important difference: if (e.g. process) innovations are spread probabilistically across the $m$ different activities of each firm, then the firms will gradually become different. One firm will have superior productivities with respect to some activities while another firm will have superior productivities with respect to other activities. This divergence is especially strong if technological change is cumulative (i.e. innovative results depend on present productivity) and if imitation is difficult (as Levin, Klevorick, Nelson and Winter, 1987, have demonstrated that it often is). In this case it becomes especially obvious that as long as interfirm division of labour between firms is not introduced, firms will concentrate their employment in a way which is exactly opposite of their comparative advantages. The reason is simple: to produce one unit of final output, it is necessary to 
produce one unit of each of the intermediate products. Employment thus have to be focused on the activities in which firms have poor performance. ${ }^{12}$

From the viewpoint of a historically given situation with constant returns to scale and with differing tasks-specific productivities of firms, the solution seems to be obvious. Overall productivity of the industrial sector will be maximised if firms are allowed to specialise fully according to their historically obtained comparative advantages. Such a specialisation also exploits the increasing returns to the application of an innovation: in the Nelson and Winter model the (probabilistic) costs of producing an innovation are fixed but there are no extra costs involved is the (smaller or larger) application of the innovation. Thus, we are apparently led to Sraffa's (1926) conclusion about the unfeasibility of competition under the conditions of increasing returns to scale. This problem is already present in the standard Nelson and Winter model where it is mainly overcome by a rather unconvincing mechanism of imitation. In the vertical model many more firms will survive but within each task of production we will see a high degree of concentration (e.g. measured by the Herfindahl index).

To decide whether a strong industrial concentration is real problem, we need to present some details about the structural specialisation of firms in the vertical model (see figure 7). First of all, it should be pointed out that the (present form of the) vertical model differ from the Nelson and Winter model with respect to an important assumption, which is not depicted by figure 7: Nelson and Winter (1982, ch. 5) assume that firms forget routines that are not performed continually. The vertical model assumes that firms are still able to perform activities although they are not practising them because of a structural specialisation. However, it is also assumed that process and product innovation are primarily related to active tasks. This means that the productivity gap between the unchanging performance of latent tasks and the best-practice performance will at some point of time make the specialisation irreversible. If demand is diminishing, this will threaten the existence of the specialised firm. 


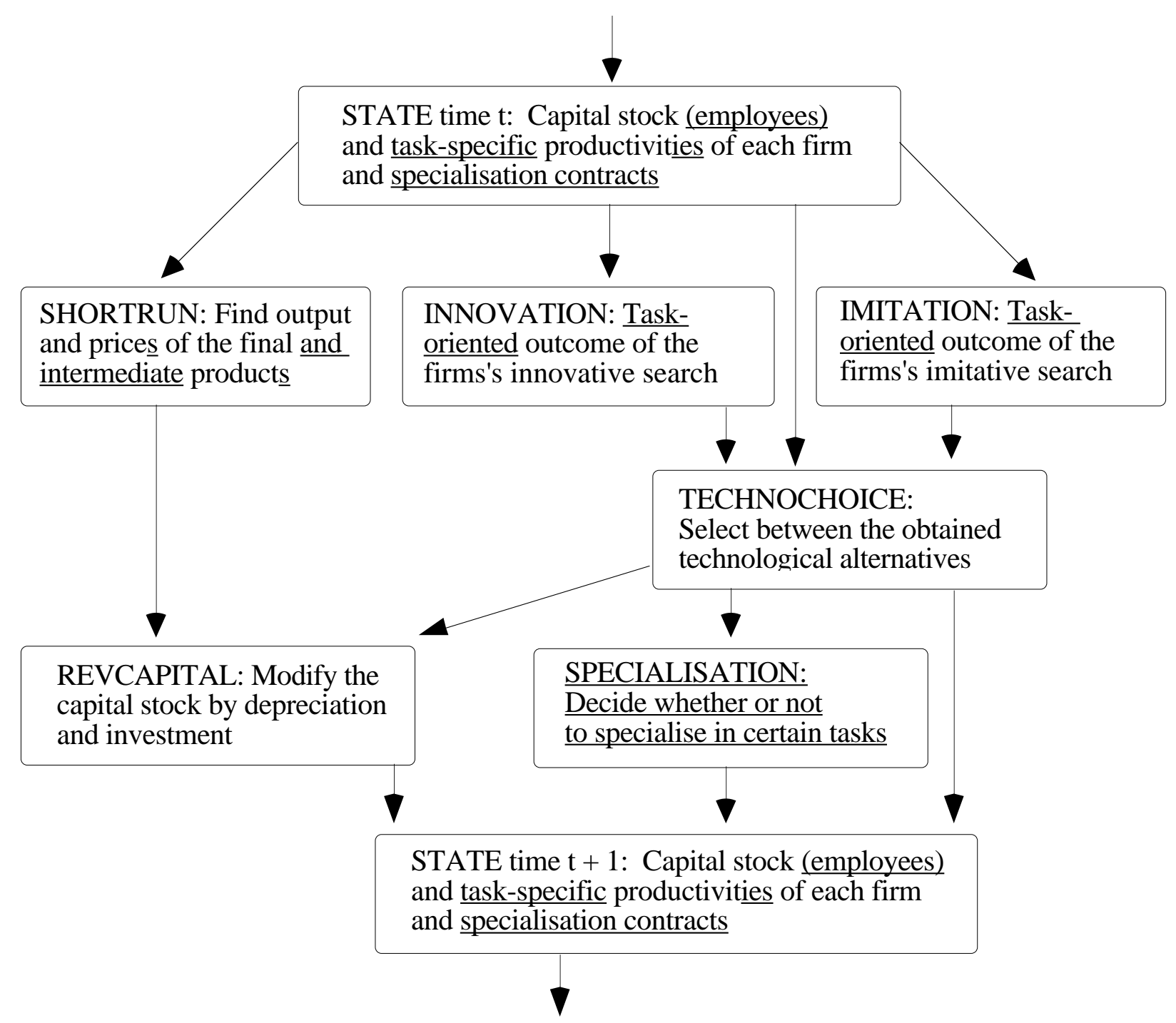

Figure 7. Main structure of the vertical model.

(Differences vis-à-vis the Nelson and Winter model are underlined.)

There are two kinds of structural specialisation: output specialisation and input specialisation. Output specialisation concerns the marketed product of the firm. This output can either be the consumer product or one of the intermediate products. In any period the output specialisation is, for reasons of simplicity, ${ }^{13}$ considered to be complete, i.e. a firm can only produce one marketed product. In a bargaining process at the end of each period the firm can suggest a new specialisation (by posting a price). ${ }^{14}$ If there are sufficient orders to obtain full capacity utilisation, the new specialisation will be applied in the next period. Input specialisation of a firm means that it partly or fully substitutes one or more of its own activities with purchased intermediate goods. By considering the posted prices for intermediate goods, the firm determines whether or not to make orders. Depending on the production capacity of the suppliers, the orders rejected or accepted wholly or partially. If the order is only partially accepted, the ordering firm has to apply a part of its labour force to supplement the purchased inputs 
with in-house production. This means that input specialisation does not have to be complete.

Given these specifications of structural specialisations, it is obvious that they are not only giving advantages to firms. A successful firm that wants to exploit its innovation has to guess about the productivity conditions of its potential customers before it sets a price on its new intermediate good. If the price is set too high, there will not be sufficient orders to allow a specialisation although it may have been profitable even with a lower price. Things are easier for latecomers to the new 'industry' selling an intermediate product. They can use the previous market price to orient themselves, but the quantity that can be sold is strictly limited, and newcomers are assumed to get the marginal orders (although they are able to influence the market price). If we allow product innovations and 'destructive' structural innovations to take place (see section 3 ), it is still more obvious that life high up in the production trees is not at all easy: a major product innovation means that the quantity demanded for a whole subtree will immediately diminish, and a 'destructive' structural innovation means that a subtree will totally disappear. 15

\section{Types of roundaboutness in the vertical model}

In the previous sections no attempts were made to give quantitative measures of the absolute and average height of production trees. In the stylised examples of sections 2-3 such measures were not immediately necessary. But as soon as production trees becomes slightly more complex, measurement becomes crucial to the development of the whole vertical approach. For instance, two production tree of height 20 might be quite different: the first could consist of a single chain of 20 nodes while the other could be a full binary tree with more than a million nodes. A small excursus into the history of economic analysis demonstrates that we are facing a serious measurement problems that is reflected in the confusion around the concept of roundaboutness. Actually, we have at least four different concepts of roundaboutness that for convenience can be related to great economists: Böhm-Bawerkian roundaboutness, Schumpeterian roundaboutness, Smithian roundaboutness and Youngian roundaboutness.

According to Böhm-Bawerk (192116), a method of production is roundabout if, in addition to labour and land, it uses intermediate goods and/or the services of capital goods. ${ }^{17}$ Böhm-Bawerk considers roundabout ('capitalistic') methods to be more productive than simple methods. But his initial definition is so broad that practically all methods of modern production are roundabout. To develop a more powerful concept, Böhm-Bawerk starts by pointing out that some methods are more roundabout than others. Then he develops methods for measuring the degree of roundaboutness. ${ }^{18}$ Finally he proposes that productivity is a positive function of the roundaboutness of 
production. With this proposition he turns not only to the theory of capital and interest but also to a (sketchy) theory of growth and development.

In the analysis we shall assume that statistics have been collected concerning the production trees like the ones depicted in figures 1-5. The production of such statistics is a near-impossible task because of limitations in the internal accounting of firms and because of their unwillingness to reveal the data they actually have. But statistics can easily be provided from the 'artificial economic systems' created by computer simulation models in the Nelson and Winter tradition of evolutionary economics. In both cases we shall assume that $n$ firms perform one or more of $m$ activities. ${ }^{19}$ The statistics collected concern the applied labour hours $L_{i j t}$, for each period $t$, each firm $i$ and each activity $j$. These data are, of course, only fully reflecting the conditions of a model of a pure labour economy. However, they can be used for calculating rough indices for more complex models and for real economies.

Böhm-Bawerk's concept of (technical) roundaboutness is developed in relation to the 'Austrian' ordering of goods according to their closeness to final consumption. The first order of goods are consumption goods, the second order of goods are used in the production of consumption goods, the third order of goods are used in the production of secondary goods, and so on. Böhm-Bawerk relates the orders of goods to their time distance from final consumption. His first class of goods is available for consumption after one period, the second class is available after two periods, etc. These classes give the background for his definition of the degree of roundaboutness of methods of producing final goods:

To calculate Böhm-Bawerkian roundaboutness, we need to measure the time distance between an economic activity and final production. For simplicity, we shall simply assume that each level in the production trees of figures 1-5 has a distance of 1 to the next level. To find the labour hours engaged at level $k, L_{k t}$, we simply add the labour engaged in all the activities at this level. Given these data, we can find the degree of roundaboutness. But it is probably more correct to use dated statistics in calculating Böhm-Bawerk's 'average period of production' for period $t=0$. To do so we need to calculate level 1 at time $t=-1$, level $k$ at time $t=-k$, etc.:

$$
R_{t}^{\mathrm{BB}}=-\sum_{t=-1}^{-\infty} t L_{t} / \sum_{t=-1}^{-\infty} L_{t}
$$

Böhm-Bawerk tried to develop his model of capital, interest and growth on the causal relationship between an increasing degree of roundaboutness and overall labour productivity. To Schumpeter increased labour productivity was based on innovation which involved another kind of roundaboutness. To implement an innovation, entrepreneurs have to make investments in advance. If we calculate the labour hours 
used in each period before the launch of the innovation at $t=0$, we have one of the possible Schumpeterian indices of roundaboutness - the average period of innovative activity:

$$
R_{t}^{\mathrm{S}}=-\sum_{t=-1}^{-\infty} t L_{t}^{\mathrm{inno}} / \sum_{t=-1}^{-\infty} L_{t}^{\mathrm{inno}}
$$

In Adam Smith's theory of the economic role of the technical division of labour, it is not (primarily) time but the number of specialised tasks that matter. This theory does not distinguish explicitly between horizontal and vertical division of labour. However, if we are interested in the vertical aspect of Smith's argument, we can calculate 'Smithian' roundaboutness (which is clearly present in his case of pin manufacturing):

$$
R_{t}^{\mathrm{AS}}=\sum_{k=1}^{\infty} k L_{k t} / \sum_{k=1}^{\infty} L_{t}
$$

where $k$ is the level in the production tree.

Young (1928) has emphasised roundaboutness in terms of the vertical and economic division of labour between firms: 'the principal economies which manifest themselves in increasing returns are the economies of capitalistic or roundabout methods of production. ... [C]ertain roundabout methods are fairly sure to become feasible and economical when their advantages can spread over the output of the whole industry. These potential economies, then, are segregated and achieved by the operations of specialised undertakings which, taken together, constitute a new industry.' This calls for a Youngian index of roundaboutness which is the same as the Smithian roundaboutness except that $k$ is now measuring single-product firms with equal distance to final consumption.

$$
R_{t}^{\mathrm{Y}}=\sum_{k=1}^{\infty} k L_{k t} / \sum_{k=1}^{\infty} L_{t},
$$

Of the different measures of roundaboutness it is the Smithian and Youngian indices that are closest to the logic of the vertical model. Both technical and economic roundaboutness are important characteristics of the division of labour within an 'Austrian' sector of production. Their difference may point to unexploited static and dynamic possibilities of specialisation. The Youngian index may itself help to reformulate the Stigler hypothesis about the relationship between the growth of the final market and the vertical disintegration and integration of the sector (see section 2). According to Stigler we expect an increasing Youngian roundaboutness in connection with a rapid exogenous growth of the consumption good market. The vertical model makes us expect the same except in the case where a few firms are already dominating the sector. In the latter case, the only chance of a firm to expand may be through vertical integration. 
The Böhm-Bawerkian and Schumpeterian concepts of the time structure of production and innovation are much more difficult to implement. But there are some possibilities. As mentioned in section 4, the vertical model's time lags emerge only in interfirm deliveries, and thus Böhm-Bawerkian roundaboutness is related to economic rather than technical division of labour (probably against the viewpoint of Böhm-Bawerk). To explore the notion of Schumpeterian roundaboutness, we need further rethinking of the original ideas. The problem is that the effects of an innovation can always be felt in the next period. To make a more interesting measure, we could take the distance from the innovation and the emergence of a productive capacity sufficient to supply potential demand. This distance will be short if the innovative firm has already a sufficient capacity and long if the innovation is performed by a relatively small firm.

\section{Conclusions}

The paper has explored the concept of production trees both informally and more formally. It has shown that many descriptive accounts for production-tree-like structures that can be found in the literature on industrial organisation and general economics can be formalised in the terms of graph theory and the related algorithms of computer science. Through this formalisation it becomes possible to handle process and product innovation in relation to a given production tree as well as the structural transformation of production trees. These results have been applied in the development of a Nelson and Winter like model that emphasise the open-ended and roundabout character of industrial production and economic specialisation. This vertical model has helped to demonstrate how the effects of innovation can be spread throughout an industrial sector. At the same time it has suggested serious coordination problems especially for upstream firms.

The vertical model is in several ways complementary to model of horizontal Schumpeterian competition developed by Nelson and Winter, although the differences should not be underestimated. Let us start with the differences, the most important of which is probably that the building of the vertical model has strongly suggested that firms are sometimes in possession of latent alternatives to their present-day specialisation, a possibility that is excluded by assumption in the standard Nelson and Winter model. Another difference is that the vertical model puts much less emphasis on imitation than the Nelson and Winter model; actually imitation can be omitted altogether. The similarities are, however, more important as suggested by figures 6-7. This is most clearly shown by the fact that the Nelson and Winter model has been crucial in the development of the vertical model. But the reformulations point beyond the narrowly defined paradigm defined by the Nelson and Winter model. 
The existence of a well-developed vertical division of labour is not an automatic outcome of the evolutionary process. It depends on the introduction of different stabilisers which make it upstream specialisation profitable. At the same time the system must delimit transaction costs so that the beneficial effects of vertical disintegration can be obtained. These and related issues demonstrate that the apparently simple revision of the Nelson and Winter model suggests new tasks for the study of an industrial dynamics. In the standard model the firms compete about exactly the same 'niche'. In order to understand the long-term coexistence of radically different types of economic behaviour, we have to transcend this limited model of Schumpeterian competition. The introduction of a number of different productive tasks that can be innovated individually creates a multi-dimensional system of competition, which allows the survival of a larger number of behavioural variants. The reason is that firms can specialise: when a firm has made an innovation with respect to one of its tasks, it decides whether or not to specialise in pursuing this task. If it does so, it exploits the innovation on a larger scale. However, it has a problem of creating a market for the intermediate product which is the output of its innovated task.

The importance of the vertical model is not least based on the fact that it combines the classical approach to the division of labour with the Schumpeterian notion of discontinuous innovation. The model demonstrates how specialisation and innovation are closely connected. At the micro-level vertical specialisation is a way in which a previously unspecialised firm can often increase the returns from its innovation. At a more aggregate level specialisation can be demonstrated to be a way of increasing the speed of the diffusion of the innovation. But the most interesting result of the repeated process of specialisation is the emergence of a complex inter-industrial system with new 'species' or 'industries'. This issue of the non-incremental emergence of industrial species is closely related to Schumpeter's vision of evolution.

\section{Notes}

1 The paper presents a modelling framework that has gradually emerged through the author's work at the Department of Business Studies, Aalborg University, partly in discussions with Bengt-Åke Lundvall and Jørgen Østergaard. Other helpful hints has been given by Christian DeBresson, Morris Teubal and Ulrich Witt. The emerging framework has been presented in a series of papers, see Andersen (1995, 1996, forthcoming-a, forthcoming-b, forthcoming-c) and Andersen and Lundvall (1996). Anne K. Jensen has assisted with the reconstruction of Nelson and Winter models and with the development of preliminary simulation models in relation to the framework. The further development of simulation models in relation to the framework will take place within the Danish Research Unit for Industrial Dynamics (DRUID).

2 The Nelson and Winter model has been summarised and reconstructed by Andersen (1994, ch. 4) and Andersen, Jensen, Madsen and Jørgensen (1996).

3 See the survey by Nelson (1995).

4 See the survey by Silverberg and Verspagen (1995) as well as Nelson (1995, 67-72) 
5 Schumpeter $(1934,159)$ points out: 'I am concerned with the truth and not with the originality of my theory. In particular I willingly base it upon that of Böhm-Bawerk as much as possible - however decidedly the latter has declined all communion. ... If Böhm-Bawerk had kept strictly to his own expression 'adoption of roundabout methods of production' and if he had followed the indication that it contains, this would have been an entrepreneurial act - one of the many subordinate cases of my concept of carrying out new combinations. He did not do this; and I believe it can be shown with the help of his own analysis that no net income would flow from the mere repetition of roundabout methods of production which have already been carried out and incorporated in the circular flow.' Instead Schumpeter's theory could give meaning to Böhm-Bawerk's idea of a positive interest on capital. (Schumpeter's sketchy ideas of roundaboutness is shortly dealt with in section 5.)

6 Other examples from forest production is found in Andersen (forthcoming-c) where there is also a sketch of relationship of the present framework to the evolution of Marshall's (1949, 222-231) industrial districts. Some relations to Adam Smith (1976) theory of the division of labour are sketched in Andersen (forthcoming-b) and Andersen and Lundvall (1996).

7 See Böhm-Bawerk (1921, 115 f.).

8 A decomposition will reveal that some of the activities are interdependent so that the graph will become a network instead of a tree. This problem is ignored in the present paper.

9 A discussion on the programming of production trees is found in Andersen (1996). The present account draws on several sources including Knuth (1973) and Roberts (1976), and, more indirectly, Palmer (1985), and Kauffman (1993).

10 In mathematics and computer science texts trees are normally depicted upside down, and the directions thus have to be reversed.

11 In the present paper no attempt is made to include the results of evolutionary modelling in the Nelson and Winter tradition. Further work may include some of the results of e.g. Winter (1984), Silverberg, Dosi, and Orsenigo (1988), Kwasnicki (1992), Chiaromonte and Dosi (1993), Dopfer (1994), Silverberg and Verspagen (1994).

12 There are many ways of overcoming the problem of counter-productive specialisation. One possibility is to create 'technology centres' and other forms of interfirm clearinghouses for the exchange of innovations which individually are of minor importance to the innovators but which as a whole is of major importance to (nationally located) industrial sectors, cf. Galli and Teubal (1996).

13 And because customers tend to reject to buy from firms that are both their suppliers and their competitors.

14 No bargaining takes place in the market for the consumption good (called product 1). This market is modelled in the same simplistic way as in the Nelson and Winter model. Consumers as a whole have in each period decided to spend a fixed amount of money on product 1 . This aggregate amount is called $D_{1 t}$. Given a supply of $Q_{1 t}$, we have a market-clearing price: $P_{1 t}=D_{1 t} / Q_{1 t}$. To give room for an increasing roundaboutness, total revenue may increase through time in a logistic manner. The background may e.g. be that here has been an exogenous product innovation with respect to the consumption good before the start of the logistic curve.

15 The description and analysis of the vertical model will later be supplemented by a report of results of simple computer simulations. This study takes place within the framework of the Danish Research Unit for Industrial Dynamics (DRUID).

16 References are made to the last German edition. Böhm-Bawerk (1891) is the English translation of the first (1889) edition. English speaking readers should be aware that although the basic arguments are upheld in the revised version of the book 'this edition is a new book: only a few sections are left entirely unrevised, nearly all of them have been expanded, and there are a number of important additions.' (Schumpeter, 1951, 155) 
17 It is in accordance with Böhm-Bawerk's approach that capital goods has not been taken into account in the present paper.

18 Böhm-Bawerk's theory of roundaboutness has been the subject of extensive controversies not least because his suggestions of measurement methods 'involve astonishing terminological and conceptual confusions' and because his terms have been used 'in a bewildering variety of senses' (Blaug, 1968, 517).

19 Both $n$ and $m$ may vary over time.

\section{References}

Andersen, E.S. (1994), Evolutionary Economics: Post-Schumpeterian Contributions, Pinter, London. (Paperback edn. is forthcoming, 1996).

Andersen, E.S. (1995), Neo- and Post-Schumpeterian Contributions to Evolutionary Economics, Paper presented at the Conference on Economics and Evolution, Arranged by the Belgian-Dutch Association for Post-Keynesian Economics, Utrecht, 10 November 1995, Department of Business Studies, Aalborg University.

Andersen, E.S. (1996), Structure and Evolution of Production Trees and Industrial Networks: A Constructive Introduction, Dept. of Business Studies, Aalborg University.

Andersen, E.S. (forthcoming-a), 'From Static Structures to Dynamics: Specialisation and Innovative Linkages', in DeBresson, C. (ed.) Economic Interdependence and Innovative Activity: An Input-Output Analysis, Elgar, Aldershot, pp. 331-353.

Andersen, E.S. (forthcoming-b), 'The Evolution of Economic Complexity: A Divisionand-Coordination-of-Labour Approach', in Helmstädter, E., and Perlman, M. (eds.), Behavioral Norms, Technological Progress and Economic Dynamics: Studies in Schumpeterian Economics, Michigan University Press, pp. 97-119.

Andersen, E.S. (forthcoming-c), 'Theories of Localised Resource-Based Growth and Development: From Marshall to New Evolutionary Economics', in Hyttinen, P., Mononen, A., and Pelli, P. (eds.), Regional Development Based on Forest Resources: Theories and Practices, Proceedings of the International Seminar 14-15 December 1995 (EFI Proceedings No. 9), European Forest Institute, Joensuu, pp. 5-16.

Andersen, E.S., Jensen, A.K., Madsen, L., and Jørgensen, M. (1996), The Nelson and Winter Models Revisited: Prototypes for Computer-Based Reconstruction of Schumpeterian Competition, DRUID Working Papers, Department of Business Studies, Aalborg University.

Andersen, E.S., and Lundvall, B.-A. (1996), National Innovation Systems and the Dynamics of the Division of Labour, Revised version of a paper presented at the third meeting of the Systems of Innovation Research Network, Söderköping Conference, September 7-10, 1995, DRUID and IKE Group, Department of Business Studies, Aalborg University.

Blaug, M. (1968), Economic Theory in Retrospect, 2nd edn., Cambridge University Press, Cambridge.

Böhm-Bawerk, E.v. (1891), The Positive Theory of Capital, Stechart, New York.

Böhm-Bawerk, E.v. (1913), 'Eine “dynamische” Theorie des Kapitalzinses', Zeitschrift für Volkswirtschaft, Sozialpolitik und Verwaltung, Vol. 22, pp. 1-62, 640-656.

Böhm-Bawerk, E.v. (1921), Positive Theorie des Kapitales. Zweite Abteilung, Erster Band von: Kapital und Kapitalzins, 4th edn., Gustav Fischer, Jena.

Chiaromonte, F., and Dosi, G. (1993), 'The Micro Foundations of Competitiveness and their Macroeconomic Implications', in Foray, D., and Freeman, C. (eds.), Technology and the Wealth of Nations: The Dynamics of Constructed Advantage, Pinter, London, pp. 107-134.

Dopfer, K. (1994), 'The Phenomenon of Economic Change: Neoclassical vs. Schumpeterian Approaches', in Magnusson (ed.) Evolutionary Approaches to Economics: The Neo-Schumpeterian Challenge, Dordrecht, Kluwer.

Galli, R., and Teubal, M. (1996), Paradigmatic Shifts in National Innovation Systems, Revised version of a paper presented at the third meeting of the Systems of Innovation 
Research Network, Söderköping Conference, September 7-10, 1995, State University of Milan and Jerusalem Hebrew University.

Gerybadze, A. (1982), Innovation, Wettbewerb und Evolution: Eine mikro- und mesoökonomische Untersuchung des Anpassungsprozesses von Herstellern und Anwendern neuer Produzentengüter, J.C.B. Mohr (Paul Siebeck), Tübingen.

Kauffman, S.A. (1993), The Origins of Order: Self-Organization and Selection in Evolution, New York and Oxford, Oxford University Press.

Knuth, D.E. (1973), 'The Art of Computer Programming: Fundamental Algorithms, Vol. 1 , Addison-Wesley, Reading, Mass.

Kwasnicki, W. (1992), Knowledge, Innovation, and Economy: An Evolutionary Exploration, Oficyna Wydawnicza Politechniki Wroclawskiej, Wroclaw (revised version will be published by Elgar).

Langlois, R.N., and Robertson, P.L. (1995), Firms, Markets and Economic Change: A Dynamic Theory of Business Institutions, Routledge, London and New York.

Levin, R.C., Klevorick, A., Nelson, R.R., and Winter, S.G. (1987), 'Appropriating the Returns from Industrial Research and Development', Brookings Papers on Economic Activity, Vol. 1987: 3.

Marshall, A. (1949), Principles of Economics: An Introductory Volume, reset version of 8th edn., Macmillan, Basingstoke and London.

Nelson, R.R., and Winter, S.G. (1982), An Evolutionary Theory of Economic Change, Belknap Press, Cambridge, Mass. and London.

Nelson, R.R. (1994), 'Economic Growth via the Coevolution of Technology and Institutions', in Leydesdorff, L., and Besselaar, P.v.d. (eds.), Evolutionary Economics and Chaos Theory: New Directions in Technology Studies, Pinter, London, pp. 21-32.

Nelson, R.R. (1995), 'Recent Evolutionary Theorizing about Economic Change', Journal of Economic Literature, Vol. 33, pp. 48-90.

Palmer, E.M. (1985), Graphical Evolution: An introduction to random graphs, wherein the most relevant probability models for graphs are described together with certain treshold functions which facilitate the careful study of the structure of a graph as it grows and specifically reveal the mysterious circumstances surrounding the abrupt appearance of the unique giant component which systematically absorbs its neighbors, devouring the larger first and ruthlessly continuing until the last isolated vertices have been swallowed up, whereupon the giant is suddenly brought under control by a spanning cycle. The text is laced with challenging exercises especially designed to instruct, and is accompanied by an appendix stuffed with useful formulas that everyone should know, Wiley \& Sons, New York.

Roberts, F.S. (1976), Discrete Mathematical Models: With Applications to Social, Biological and Environmental Problems, Prentice-Hall, Englewood Cliffs, N.J.

Romer, P.M. (1986), 'Increasing Returns and Long-Run Growth', Journal of Political Economy, Vol. 94, pp. 1002-1038.

Schumpeter, J.A. (1934), The Theory of Economic Development: An Inquiry into Profits, Capital, Credit, Interest and the Business Cycle, Oxford University Press, London.

Schumpeter, J.A. (1951), Ten Great Economists: From Marx to Keynes, 1969 edn., Foreward by E. B. Schumpeter, Oxford University Press, New York.

Silverberg, G., Dosi, G., and Orsenigo, L. (1988), 'Innovation, Diversity and Diffusion: A Self-Organization Model', Economic Journal, Vol. 98, pp. 1032-1054.

Silverberg, G., and Verspagen, B. (1994), 'Collective Learning, Innovation and Growth in a Boundedly Rational, Evolutionary World', Journal of Evolutionary Economics, Vol. 4, pp. 207-226.

Silverberg, G., and Verspagen, B. (1995), Evolutionary Theorizing on Economic Growth, (to appear in Dopfer, K., The Evolutionary Principles of Economics, Kluwer), MERIT, University of Limburg.

Smith, A. (1976), An Inquiry into the Nature and Causes of the Wealth of Nations, 2 vols., ed. R.H. Cambell and A.S. Skinner, Clarendon, Oxford.

Sraffa, P. (1926), 'The Laws of Returns Under Competitive Conditions', Economic Journal, Vol. 36, pp. 535-550.

Stigler, G.J. (1951), 'The Division of Labour is Limited by the Extent of the Market', Journal of Political Economy, Vol. 59, pp. 185-93. 
Taylor, F.W. (1911), The Principles of Scientific Management, Harper, New York and London.

Winter, S.G. (1984), 'Schumpeterian Competition in Alternative Technological Regimes', Journal of Economic Behavior and Organization, Vol. 5, pp. 287-320.

Yang, X., and Ng, Y.-K. (1993), Specialization and Economic Organization: A New Classical Microeconomic Framework, North-Holland, Amsterdam.

Young, A.A. (1928), 'Increasing Returns and Economic Progress', Economic Journal, Vol. 38 , pp. $527-542$. 


\section{$\mathbf{D}_{\text {anish }} \mathbf{R}_{\text {esearch }} \mathbf{U}_{\text {nit for }} \mathbf{I}_{\text {ndustrial }} \mathbf{D}_{\text {ynamics }}$}

The Research Programme

The DRUID-research programme is organised in 3 different research themes :

\section{- The firm as a learning organisation}

- Competence building and inter-firm dynamics

- The learning economy and the competitiveness of systems of innovation

In each of the three areas there is one strategic theoretical and one central empirical and policy oriented orientation.

\section{Theme A: The firm as a learning organisation}

The theoretical perspective confronts and combines the ressource-based view (Penrose, 1959) with recent approaches where the focus is on learning and the dynamic capabilities of the firm (Dosi, Teece and Winter, 1992). The aim of this theoretical work is to develop an analytical understanding of the firm as a learning organisation.

The empirical and policy issues relate to the nexus technology, productivity, organisational change and human ressources. More insight in the dynamic interplay between these factors at the level of the firm is crucial to understand international differences in performance at the macro level in terms of economic growth and employment.

\section{Theme B: Competence building and inter-firm dynamics}

The theoretical perspective relates to the dynamics of the inter-firm division of labour and the formation of network relationships between firms. An attempt will be made to develop evolutionary models with Schumpeterian innovations as the motor driving a Marshallian evolution of the division of labour.

The empirical and policy issues relate the formation of knowledge-intensive regional and sectoral networks of firms to competitiveness and structural change. Data on the structure of production will be combined with indicators of knowledge and learning. IO-matrixes which include flows of knowledge and new technologies will be developed and supplemented by data from case-studies and questionnaires. 


\section{Theme C: The learning economy and the competitiveness of systems of innovation.}

The third theme aims at a stronger conceptual and theoretical base for new concepts such as 'systems of innovation' and 'the learning economy' and to link these concepts to the ecological dimension. The focus is on the interaction between institutional and technical change in a specified geographical space. An attempt will be made to synthesise theories of economic development emphasising the role of science based-sectors with those emphasising learning-by-producing and the growing knowledge-intensity of all economic activities.

The main empirical and policy issues are related to changes in the local dimensions of innovation and learning. What remains of the relative autonomy of national systems of innovation? Is there a tendency towards convergence or divergence in the specialisation in trade, production, innovation and in the knowledge base itself when we compare regions and nations?

\section{The Ph.D.-programme}

There are at present more than $10 \mathrm{Ph}$.D.-students working in close connection to the DRUID research programme. DRUID organises regularly specific Ph.D-activities such as workshops, seminars and courses, often in a co-operation with other Danish or international institutes. Also important is the role of DRUID as an environment which stimulates the Ph.D.-students to become creative and effective. This involves several elements:

- access to the international network in the form of visiting fellows and visits at the sister institutions

- participation in research projects

- access to supervision of theses

- access to databases

Each year DRUID welcomes a limited number of foreign Ph.D.-students who wants to work on subjects and project close to the core of the DRUID-research programme.

\section{External projects}

DRUID-members are involved in projects with external support. One major project which covers several of the elements of the research programme is DISKO; a comparative analysis of the Danish Innovation System; and there are several projects involving international co-operation within EU's 4th Framework Programme. DRUID is open to host other projects as far as they fall within its research profile. Special attention is given to the communication of research results from such projects to a wide set of social actors and policy makers. 


\section{DRUID Working Papers}

96-1 Lundvall, Bengt-Åke: The Social Dimension of the Learning Economy. (ISBN 87-7873-000-7)

96-2 Foss, Nicolai J.: Firms, Incomplete Contracts and Organizational Learning. (ISBN 87-7873-001-5)

96-3 Dalum, Bent and Villumsen, Gert:Are OECD Export Specialisation Patterns 'Sticky?' Relations to the Convergence-Divergence Debate. (ISBN 87-7873-002-3)

96-4 Foss, Nicolai J: Austrian and Post-Marshallian Economics: The Bridging Work of George Richardson. (ISBN 87-7873-003-1)

96-5 Andersen, Esben S., Jensen, Anne K., Madsen, Lars and Jørgensen, Martin: The Nelson and Winter Models Revisited: Prototypes for Computer-Based Reconstruction of Schumpeterian Competition. (ISBN 87-7873-005-8)

96-6 Maskell, Peter: Learning in the village economy of Denmark. The role of institutions and policy in sustaining competitiveness. (ISBN 87-7873-006-6)

96-7 Foss, Nicolai J. \& Christensen, Jens Frøslev: A Process Approach to Corporate Coherence. (ISBN 87-7873-007-4)

96-8 Foss, Nicolai J.: Capabilities and the Theory of the Firm. (ISBN 87-7873-008-2)

96-9 Foss, Kirsten: A transaction cost perspective on the influence of standards on product development: Examples from the fruit and vegetable market.

(ISBN 87-7873-009-0)

96-10 Richardson, George B.: Competition, Innovation and Increasing Returns. (ISBN 87-7873-010-4)

96-11 Maskell, Peter: Localised low-tech learning in the furniture industry. (ISBN 87-7873-011-2)

96-12 Laursen, Keld: The Impact of Technological Opportunity on the Dynamics of Trade Performance. (ISBN 87-7873-012-0)

96-13 Andersen, Esben S.: The Evolution of an Industrial Sector with a Varying Degree of Roundaboutness of Production. (ISBN 87-7873-013-9) 


\section{Information for subscribers.}

Subscription price for 1996 is 600 DKR (about 20 papers). The rate for single issues is $40 \mathrm{DKR}$. It is possible to make a commitment to an exchange of papers from related departments or research teams. All correspondence concerning the DRUID Working Papers should be send to:

Mette Madsen

Fibigerstræde 4, DK-9220 Aalborg OE

Tel. 45981542 11-2945

Fax. 4598156013

E-mail: mm@business.auc.dk 